\title{
Carotid artery stenting: current and emerging options
}

This article was published in the following Dove Press journal:

Medical Devices: Evidence and Research

20 October 2014

Number of times this article has been viewed

\author{
Simon Morr ${ }^{1,4}$ \\ Ning Lin ${ }^{1,4}$ \\ Adnan H Siddiqui ${ }^{1-5}$ \\ 'Department of Neurosurgery, \\ 2Department of Radiology, School of \\ Medicine and Biomedical Sciences, \\ ${ }^{3}$ Toshiba Stroke and Vascular Research \\ Center, University at Buffalo, State \\ University of New York, ${ }^{4}$ Department \\ of Neurosurgery, Gates Vascular \\ Institute, Kaleida Health, ${ }^{5}$ acobs \\ Institute, Buffalo, NY, USA
}

\begin{abstract}
Carotid artery stenting technologies are rapidly evolving. Options for endovascular surgeons and interventionists who treat occlusive carotid disease continue to expand. We here present an update and overview of carotid stenting devices. Evidence supporting carotid stenting includes randomized controlled trials that compare endovascular stenting to open surgical endarterectomy. Carotid technologies addressed include the carotid stents themselves as well as adjunct neuroprotective devices. Aspects of stent technology include bare-metal versus covered stents, stent tapering, and free-cell area. Drug-eluting and cutting balloon indications are described. Embolization protection options and new direct carotid access strategies are reviewed. Adjunct technologies, such as intravascular ultrasound imaging and risk stratification algorithms, are discussed. Bare-metal and covered stents provide unique advantages and disadvantages. Stent tapering may allow for a more fitted contour to the caliber decrement between the common carotid and internal carotid arteries but also introduces new technical challenges. Studies regarding free-cell area are conflicting with respect to benefits and associated risk; clinical relevance of associated adverse effects associated with either type is unclear. Embolization protection strategies include distal filter protection and flow reversal. Though flow reversal was initially met with some skepticism, it has gained wider acceptance and may provide the advantage of not crossing the carotid lesion before protection is established. New direct carotid access techniques address difficult anatomy and incorporate sophisticated flow-reversal embolization protection techniques. Carotid stenting is a new and exciting field with rapidly advancing technologies. Embolization protection, low-risk deployment, and lesion assessment and stratification are active areas of research. Ample room remains for further innovations and developments.
\end{abstract}

Keywords: carotid devices, carotid stent, embolization protection, carotid stenosis, endovascular carotid

\section{Introduction}

Ramsay-Hunt reported in 1913 the clinicopathological findings of what he called "thrombotic hemiplegia," where stroke patients were found to have a weakened carotid pulse, and postmortem pathology revealed carotid thrombus ipsilateral to gross ischemic changes in the brain. ${ }^{1}$ Cervical carotid artery stenosis was recognized by $\mathrm{C}$ Miller Fisher in the 1950 s to be a major cause of stroke. ${ }^{2}$ Carotid endarterectomy has been implemented in the at-risk patient pool with significant success in reducing the risk of subsequent stroke compared to medical therapy alone. ${ }^{3-5}$ The innovative options offered by endovascular techniques have created a rapidly evolving field of medical devices whose judicious use allows for safe, often less invasive, alternatives to carotid
Correspondence: Adnan H Siddiqui University at Buffalo Neurosurgery, 100 High Street, Suite B4, Buffalo, NY 14203, USA

Tel $I+7162181000$

Fax I+ 7168597479

Email asiddiqui@ubns.com 
endarterectomy for carotid revascularization. Carotid stenting is now a widely accepted alternative to endarterectomy in specific situations. ${ }^{6,7}$ We here systematically describe the current state of carotid revascularization devices and the evidence to support them. Although endovascular treatment of occlusive carotid disease is indispensable during acute stroke intervention, we will focus predominantly on elective and semielective revascularization.

The carotid artery is unique because of its end organ. Whereas the primary concern during revascularization in peripheral vessels is restoration of flow and hemodynamic balance, even minor distal embolization in the carotid artery can be associated with devastating neurological injury. Conversely, although distal embolization remains a concern when instrumenting and manipulating intracranial vasculature, these vessels lack significant muscularity and have a lower resistance bed. The unique goal of carotid device technology is to achieve adequate endoluminal recanalization against a centripetal muscular force, while minimizing distal embolic events.

Conceptually, we categorize carotid technologies into three groups: stent, balloon angioplasty, and embolization prevention devices. Other miscellaneous technologies are also presented.

\section{Stents}

\section{Background}

A stent is a scaffolding device that is often tubular and is used to hold tissue in a specific stretched or taut position. Modern intravascular stents are available in balloonexpandable and self-expanding varieties. In the setting of carotid bifurcation disease where prominent chronic compressive forces and a substantial drop in caliber between the common and internal carotid arteries (ICAs) as well as their mobile nature, self-expanding stents (eg, Wallstent; Boston Scientific, Natick, MA, USA) have become standard of care. ${ }^{8-11}$ Though early carotid interventionists reserved balloon-expandable stents for especially tortuous, ostial, and very calcified lesions, ${ }^{8}$ advances in stent technology have reduced the role of this type of stent even in those lesions. The two most common alloys for carotid stents are cobalt-chromium and nickel-titanium (known as nitinol). Self-expanding stents are usually manufactured in a readyto-use compressed form within a catheter-based sheath that functions as a delivery system. After insertion into the target artery, expansion is achieved by "unsheathing" the stent, at which time the mechanically predetermined centrifugal spring-like force is no longer neutralized by the sheath structure and the stent expands. ${ }^{12}$

\section{Carotid stenting trials}

The initial impetus to develop endovascular alternatives to endarterectomy was to provide a noninferior treatment modality for patients who were suboptimal surgical candidates. Medical morbidities that increase surgical risk include severe cardiac, pulmonary, and renal disease. Poor anatomical factors include a very high carotid bifurcation, in which case carotid access/exposure poses an inevitable risk of mandibular dislocation. Historically, adjunct procedures to improve access to the carotid artery have included mandibulonasal wiring, mandibular subluxation, and mandibular condyle resection. ${ }^{13-15}$ Other anatomic considerations include previous extensive neck dissection and/or irradiation. Patients with previous injury to nervous structures with partial laryngeal palsy are at high risk for developing debilitating and life-altering pharyngolaryngeal dysfunction with surgery contralateral to the compromised side. Prohibitive spinal immobility and other anatomic hindrances to intubation are also considerations. ${ }^{16,17}$

Early endovascular alternatives to carotid endarterectomy were predominantly balloon-based. A randomized study comparing carotid endarterectomy and angioplasty was terminated after enrolling only ten endarterectomy and seven angioplasty patients due to a high rate of mortality in the latter group. ${ }^{18}$ The Carotid and Vertebral Artery Transluminal Angioplasty Study investigators found no significant difference in rates of stroke or death between carotid balloon angioplasty with or without stenting and endarterectomy in symptomatic carotid stenosis cases. ${ }^{19}$ However, the study was underpowered to make a claim of equal efficacy.

Trials conducted in North America (Stenting and Angioplasty with Protection in Patients at High Risk for Endarterectomy [SAPPHIRE]) and Europe (Endarterectomy versus Angioplasty in Patients with Symptomatic Severe Carotid Stenosis [EVA-3S] and Stent-Protected Angioplasty versus Carotid Endarterectomy [SPACE]) attempted to demonstrate noninferiority for stenting compared to endarterectomy. ${ }^{20-22}$ The SAPPHIRE trial enrolled highrisk (eg, significant cardiac disease, recurrent stenosis, and age $>80$ years) symptomatic and asymptomatic patients. ${ }^{22}$ The composite end point (death, stroke, or myocardial infarction [MI] within 30 days of intervention or death or ipsilateral stroke within 1 year) occurred less frequently 
in the stenting with embolic protection group compared with the endarterectomy group in a noninferiority analysis (12.2\% versus $20.1 \%, P=0.004)$. The EVA-3S trial, on the other hand, was terminated prematurely because of safety and futility concerns. A significant increase in 30-day risk of stroke or death was found in the stenting group compared to the endarterectomy group $(9.6 \%$ versus $3.9 \%, P=0.01) .{ }^{20}$ Follow-up results demonstrated a higher cumulative probability of periprocedural stroke or death and nonprocedural ipsilateral stroke after up to 4 years in the stenting group (11.1\% in the stenting group versus $6.2 \%$ in the endarterectomy group, $P=0.03) .{ }^{23}$ In the SPACE trial, no significant difference was found in the 30-day and 2-year risk of stroke or death between stenting and endarterectomy. ${ }^{24}$ Nevertheless, the study failed to prove noninferiority, likely due to insufficient power. Additionally, the rate of recurrent stenosis was higher in the stenting group. Though neither European trial proved noninferiority of stenting, data suggested that the greatest risk was concentrated in the periprocedural period and that the risk of mid-term to long-term recurrent stroke was low. Both were criticized for lacking standardization of stent type and neurointerventionist experience.

More recently, the International Carotid Stenting Study (ICSS) investigators randomized 1,713 patients with $>50 \%$ symptomatic carotid stenosis in 50 mostly European centers. ${ }^{25}$ Within the 120-day follow-up period, the incidence of stroke, death, or periprocedural MI was significantly higher in the stenting group. Endarterectomy was significantly more likely to be associated with cranial neuropathies and wound complications. In a subsequent subset analysis, significantly more ischemic brain lesions were found on magnetic resonance (MR) diffusion-weighted imaging after stenting compared to endarterectomy. ${ }^{26}$

The Carotid Revascularization Endarterectomy versus Stenting Trial (CREST) is the largest randomized controlled trial comparing stenting with embolic protection "whenever feasible" and endarterectomy in both symptomatic and asymptomatic carotid stenosis. ${ }^{7}$ Patients from 117 centers in North America were enrolled in the trial. Up to 4 years of follow-up data were collected. No statistical difference was noted in the primary end point of a composite of 30-day stroke, MI, or death. Isolation of the end points revealed a higher risk of periprocedural stroke or death in the stenting group ( $4.4 \%$ versus $2.3 \%, P=0.005)$, whereas $\mathrm{MI}$ was more common in the endarterectomy group $(1.1 \%$ versus $2.3 \%, P=0.03)$. The change in measured outcomes in this trial compared to previous trials has been attributed to improving technology and advanced interventionist skills. More comprehensive screening protocols have also been invoked; for example, the overall rate of MI was much higher in CREST than in ICSS (1.7\% versus $0.5 \%)$, likely due to cardiac biomarkers being screened in all patients in CREST and only in patients complaining of cardiac symptoms in ICSS.

The CREST-2 trial currently under way utilizes a fourarmed parallel study design to compare composite 30-day stroke and death outcome differences between medical therapy alone versus endarterectomy and stenting, respectively, in conjunction with best medical therapy, in an asymptomatic patient pool. ${ }^{27}$ Once the two parallel studies are completed, the difference in gain, if any, from adding one of the two revascularization procedures to medical therapy will be compared.

\section{Evolution of stent technology}

The Wallstent (Boston Scientific), initially approved for biliary use in Europe, has subsequently been approved for use in various internal organs and the iliac artery. ${ }^{10,28,29}$ Use in the carotid artery has been off-label. Given its limited expansion force, the diameter of the Wallstent must usually be oversized by $2-3 \mathrm{~mm}$ relative to the lumen of the ICA. Additionally, it is difficult to predict where and to what degree the stent will be foreshortened, challenging the interventionist's capacity to ensure that the lesion is entirely crossed by the stent. Further, its sharp wire ends create the potential for intimal injury. In cases of vessel tortuosity, this problem is compounded by unevenly distributed circumferential pressure, predisposing to kinking at bends and flaring at the ends. The Wallstent is an alloy of cobalt, chromium, nickel, molybdenum, iron, manganese, and stainless steel woven into a cylindrical superstructure. Tantalum has been added to its composition to enhance radiopacity. The Symphony (Boston Scientific) is a welded nitinol stent that is more rigid than the Wallstent and has a tendency to kink in tortuous vessels. It is thus primarily used for common carotid and brachiocephalic arteries with fairly straight trajectories. It has been reported to foreshorten less than $8 \% .^{30}$ The SMART Stent (Cordis Corporation, Bridgewater, NJ, USA) is laser cut from a single nitinol tube and has a deployment mechanism and wall coverage that are similar to the Wallstent. The Acculink (Abbott Vascular, Abbott Park, IL, USA) was specifically designed for use in the extracranial carotid artery. Numerous other unique sophisticated stent designs are available at present, some of which are listed in Table 1. 
Table I Characteristics of commonly used carotid stents

\begin{tabular}{|c|c|c|c|c|c|}
\hline Stent & Manufacturer & Cell type & $\begin{array}{l}\text { Free cell area } \\
\left(\mathrm{mm}^{2}\right)\end{array}$ & $\begin{array}{l}\text { Nontaper } \\
\text { option }\end{array}$ & $\begin{array}{l}\text { Taper } \\
\text { option }\end{array}$ \\
\hline Wallstent & Boston Scientific (Natick, MA, USA) & Closed & 1.08 & $Y$ & $\mathrm{~N}$ \\
\hline Xact & Abbott Vascular (Abbott Park, IL, USA) & Closed & 2.74 & Y & Y \\
\hline NexStent & Boston Scientific & Closed & 4.70 & $\mathrm{~N}$ & Y \\
\hline Precise & Cordis (Bridgewater, NJ, USA) & Open & 5.89 & Y & $\mathrm{N}$ \\
\hline Exponent & Medtronic (Minneapolis, MN, USA) & Open & 6.51 & Y & Y \\
\hline Protégé & Covidien (Irvine, CA, USA) & Open & $10.7 \mid$ & Y & Y \\
\hline Acculink & Abbott Vascular & Open & 11.48 & Y & Y \\
\hline Zilver $518^{\circledR} \mathrm{RX}$ & Cook Medical (Bloomington, IN, USA) & Open & 12.76 & Y & $\mathrm{N}$ \\
\hline Cristallo Ideale & Medtronic & $\begin{array}{l}\text { Hybrid: closed-cell center; } \\
\text { open-cell ends }\end{array}$ & & Y & \\
\hline Sinus-Carotid-Rx & Optimed (Ettlingen, Germany) & $\begin{array}{l}\text { Hybrid: open-cell center; } \\
\text { closed- cell ends }\end{array}$ & & Y & \\
\hline
\end{tabular}

Abbreviations: $\mathrm{N}$, no; $\mathrm{Y}$, yes.

\section{Open-cell versus closed-cell design}

The open-cell versus closed-cell distinction identifies the free-cell area or the amount of space between the latticework of a stent. In closed-cell stents, each free space (cell) between the tines of a stent is completely separated from all other spaces by tines, whereas in open-cell designs the cell is connected to other cells through incomplete tines. An open-cell stent allows for larger uncovered gaps and is more malleable, making it better suited for tortuous areas. The reduced need for manipulation associated with this stent design is likely to reduce embolic potential, as well as kinking. Conversely, the greater free-cell area allows for more exposed plaque, possibly increasing embolic potential. ${ }^{31}$ Closed-cell stents may provide greater plaque coverage but are more rigid and require more vigorous manipulation to implant. Closed-cell stents are associated with possibly decreased levels of platelet aggregation. ${ }^{32-34}$ In addition, elevated carotid artery velocities have been demonstrated in closed-cell stents. ${ }^{35}$ However, the implications for clinical correlates and restenosis rate are unclear.

A prospective randomized trial found no significant difference in diffusion restricting lesions on MR imaging when comparing closed- and open-cell designs ${ }^{36} \mathrm{~A}$ retrospective comparison found that the open-cell design was associated with significantly fewer diffusion-weighted detectable embolic events on MR imaging when carotid atherosclerosis was treated without distal protection devices. ${ }^{37}$ However, the difference in rate of clinical events did not reach statistical significance. It should be noted that these retrospective studies do not address the possibility that the embolic imaging findings may be related to the necessary process of crossing the lesions with the protection device itself before distal protection is established.
Some studies suggest that closed-cell stents afford more protective lesion coverage and a possible decrease in transient ischemic attacks. ${ }^{38,39}$ Yet, another study found no statistically significant differences in neurologic complications, stroke, and mortality risk between carotid stent cell designs. ${ }^{40}$

It should be noted that dichotomizing free-cell area into "open" and "closed" cell designs is slightly misleading. Not only is there variability in quantitative free-cell area among so-called "open-cell" stents, but also the final freecell area will inevitably be significantly affected by the size of stent chosen for a particular carotid artery caliber and lesion - ie, whether the interventionist chooses to "oversize" or "undersize." ${ }^{41}$ Additionally, newer hybrid stent designs have attempted to combine the benefits of open- and closed-cell designs by introducing a variable free-cell area in different regions of the stent (Table 1).

\section{Bare-metal versus covered stents}

Some investigators suggest that bare-metal stents with insufficient luminal wall coverage predispose to periprocedural embolic events and increase long-term embolic potential due to the exposed atherosclerotic surface. ${ }^{42}$ Studies have been mixed in demonstrating a clinical difference between bare-metal and covered stents. Materials used to cover stents include porous expanded polytetrafluoroethylene polymer and semipermeable porous silicone-polyurethane. ${ }^{43-46} \mathrm{An}$ extensive review of covered stents from a materials engineering perspective has been published. ${ }^{47}$

One disadvantage of covered stents is their propensity for blocking branch vessels. Because carotid artery disease usually involves the carotid bifurcation and the cervical carotid artery, this is unlikely to be a major concern except in the setting where the stent is anticipated to cross the external carotid 
artery (ECA). Although occlusion of the extracranial carotid circulation may be of limited consequence in the setting of robust ICA flow, patients with long-standing cerebrovasculopathy and chronic ICA low-flow states are often dependent on extensive networks of angiographically visible and hidden extracranial-to-intracranial anastomoses. ${ }^{48}$

A covered stent with an opening on the side has been devised but has not gained wide acceptance because of the difficulty in deploying it with the opening in the exact orientation of the ECA. A recent stent design places slits on a covered stent in the direction of the long axis of the stent. This design is intended to allow blood flow into the ECA while covering the plaque and preventing embolization of atherosclerotic debris. ${ }^{7}$ This device is awaiting clinical testing.

\section{Stent tapering}

The caliber of the common carotid artery (CCA) is usually significantly and predictably larger than that of the ICA. Endovascular attempts to address this issue have included the use of tapered stent designs. In a nontapered stent, the distal and proximal diameters of the stent are engineered to be the same. Manufacturers have argued that self-expanding stents are naturally "self-tapering" and will contour to the inner lumen of the carotid artery. Tapered stents provide a decrement in diameter in the proximal and distal edges. Two subcategories are available. One type, represented by the Acculink and Xact stents (Abbott Vascular, Abbott Park, IL, USA), incorporates a gradual diminution of diameter, referred to as a conical taper. A "shouldered" variety, exemplified by the Protégé stent (Covidien, Irvine, CA, USA), has a punctuated decrease in stent caliber. The transitional point is referred to as the shoulder and should be positioned at the level of the ECA takeoff. Data regarding possible benefits of tapered stents is still inconclusive. ${ }^{49}$

\section{Unfavorable anatomy and direct carotid access}

Direct carotid artery puncture provides enhanced access in tortuous vessels. ${ }^{50,51}$ Initially reported in intracranial angioplasty and stenting cases, ${ }^{52}$ it has now been extended for use in carotid bifurcation lesions. Although age $>70$ or 80 years is often presented as an intrinsic independent risk factor for embolic events with endovascular stenting, close reevaluation has found that unfavorable arch anatomy is most important in predisposing for adverse embolic events, rather than age alone. ${ }^{53-55}$ Vessel tortuosity and atherosclerotic aortic arch disease were found to be the predominant factors contributing to the increased rate of stroke associated with carotid stenting in patients $>70$ years compared with carotid stenting in younger patients and endarterectomy among all ages; this suggests that the increased risk of embolic events is likely related to difficult access. ${ }^{54,55}$ When patients with an acute angle between the aortic arch and the stented CCA were compared to patients with more favorable arch anatomy in a high-volume single-center retrospective study, a significant difference $(P=0.0073)$ in adverse embolic events was observed. ${ }^{53}$ When controlling for arch anatomy, no statistically significant difference between patients aged $\geq 80$ years and $<80$ years could be found.

\section{Balloon angioplasty for in-stent restenosis Cutting balloon}

In-stent restenosis has been reported in $8 \%$ of carotid stenting cases. ${ }^{56}$ The CREST investigators reported a $6 \%$ restenosis rate in both stenting and surgical endarterectomy cases. ${ }^{7}$ Consensus and rigorous evidence are lacking for the management of in-stent restenosis. Successful use of a cutting balloon, previously well known to interventional cardiologists for partial atherectomy in cases of primary or delayed lesion recurrence after coronary stenting, has been reported in small carotid stenting case series. ${ }^{57-59}$ The same technology has been successfully reported for severely calcified primary carotid lesions as an adjunct to stenting to minimize hemodynamic instability from carotid bulb compression. ${ }^{60}$

\section{Drug-eluting balloon}

Drug-eluting balloon technology has a long track-record in the coronary arteries and has recently been applied to the carotid artery. The dominant opinion is that these devices should not be used for direct mechanical dilatation but should rather be used as a drug delivery system once predilation has been successfully achieved. ${ }^{61,62}$

\section{Embolization prevention}

Statistically significant microembolic events have been recorded using transcranial Doppler ultrasonography during carotid stenting. ${ }^{63}$ Noninferiority of stenting with distal protection compared to historical results with endarterectomy has been demonstrated ${ }^{64}$ and was confirmed in the prospective randomized controlled SAPPHIRE trial. ${ }^{22}$ Periprocedural neuroprotection is thought to provide clinical benefit by preventing distal migration of macroscopic and microscopic emboli that may cause clinically significant ischemic events. 
Three categories of embolic prevention systems are currently available. Distal nonocclusive systems ideally prevent distal embolization while preserving distal flow. Distal occlusive systems prevent flow of both blood and embolic material distally. Proximal devices occlude CCA and ECA flow, thereby producing flow reversal from the ICA, removing embolic material from the carotid bifurcation region into the CCA, and, eventually, returning blood via a filter into the venous system (GORE Flow Reversal System; WL Gore and Associates, Flagstaff, AZ, USA) or direct aspiration (Mo.Ma; Medtronic, Minneapolis, MN, USA).

\section{Distal protection}

Stenting with distal filtration technologies (distal nonocclusive systems) demonstrated noninferiority to endarterectomy, and outcomes following multicenter cohort studies as well as the SAPPHIRE trial were promising. ${ }^{22,65,66}$ The Angioguard (Cordis, Bridgewater, NJ, USA) used in SAPPHIRE is a low profile guidewire-based filtering device that allows for easy simultaneous delivery of stents and balloons. The wire is then pulled out at the end of the case, along with the filter basket. The NeuroShield Cerebral Protection System (MedNova, Galway, UK; subsequently acquired by Abbott Vascular and marketed as the Emboshield) is a temporary implantable design composed of a porous nonocclusive polyurethane membrane deployed over a preformed nitinol expansion wire construct. A retrieval system is included with a flexible distal portion to the outer catheter that expands as the inner catheter is passed. Commonly used distal protection devices are listed in Table 2.

Table 2 Distal embolization protection devices

\begin{tabular}{|c|c|c|c|c|}
\hline Device & Manufacturer & $\begin{array}{l}\text { Pore } \\
\text { size }(\mu \mathrm{m})\end{array}$ & $\begin{array}{l}\text { Vessel } \\
\text { size }(\mathbf{m m})\end{array}$ & $\begin{array}{l}\text { Fixed } \\
\text { wire }\end{array}$ \\
\hline $\begin{array}{l}\text { Gore } \\
\text { Embolic } \\
\text { Filter }\end{array}$ & $\begin{array}{l}\text { Gore (Newark, } \\
\text { DE, USA) }\end{array}$ & 100 & $2.5-5.5$ & $Y$ \\
\hline Emboshield & $\begin{array}{l}\text { Abbott (Chicago, } \\
\text { IL, USA) }\end{array}$ & 120 & $2.5-7$ & $\mathrm{~N}$ \\
\hline Spider & $\begin{array}{l}\text { Covidien (Irvine, } \\
\text { CA, USA) }\end{array}$ & $50-300$ & $3.0-7.0$ & $\mathrm{~N}$ \\
\hline Accunet & Abbott & 125 & $3.2-5$ & Y \\
\hline $\begin{array}{l}\text { FilterWire } \\
\text { EZ }\end{array}$ & $\begin{array}{l}\text { Boston Scientific } \\
\text { (Natick, MA, USA) }\end{array}$ & 110 & $3.5-5.5$ & Y \\
\hline FiberNet & $\begin{array}{l}\text { Medtronic } \\
\text { (Minneapolis, } \\
\text { MN, USA) }\end{array}$ & $>40$ & $3.5-7$ & Y \\
\hline Angioguard & $\begin{array}{l}\text { Cordis } \\
\text { (Bridgewater, } \\
\text { NJ, USA) }\end{array}$ & 100 & $4.5-7.5$ & $Y$ \\
\hline
\end{tabular}

Abbreviations: $\mathrm{N}$, no; $\mathrm{Y}$, yes.
That distal protection devices perform their intended function of catching emboli is clear, ${ }^{67-69}$ yet the incidence of periprocedural ischemic events has not been found to be affected by the load of embolic material found in distal filters ${ }^{67-71}$ Despite initially promising multicenter results, retrospective studies in which distal protection devices were used have not shown significantly improved outcomes, though a trend toward decreased risk of embolic ischemic events may be present. ${ }^{72}$ However, it should be noted that in the United States, carotid stenting is not reimbursed by Medicare unless it is performed with distal embolic protection.

Several disadvantages of distal protection devices have been described. These devices must be advanced across the stenotic lesion before embolic protection can be established; and during this process, distal embolization may occur. Their size is typically in the range of 3-French, and therefore they are generally stiffer and bulkier than proximal occlusion devices, increasing navigation difficulty and the likelihood of aggressive vessel/intimal manipulation across tortuous vessels or critically stenotic carotid arteries. ${ }^{73}$ They are also frequently associated with focal vasospasm and, infrequently, vessel injury. Further, retrieval and removal of a deployed protection device may provide yet another opportunity for periprocedural distal embolization. ${ }^{30,74,75}$ Acute periprocedural distal stent occlusion has been reported as well. ${ }^{76}$ One explanation for this potentially devastating complication may be a phenomenon known as "slow flow," in which focal flow diminution immediately proximal to the distal filter device may predispose to a $>9 \% 30$-day risk of stroke or death, and was found to occur in approximately $10 \%$ of carotid stenting cases in a single-center registry. ${ }^{77}$ Previously symptomatic and older patients were more likely to be affected. Indeed, an unacceptably high rate of complications has been reported in older patients undergoing carotid artery stenting in several studies utilizing distal protection devices. ${ }^{78-80}$ Nevertheless, rapid advances in endovascular stenting and associated protection techniques have been associated with improved outcomes in the recent past; the anticipation is that this trend will continue and new technologies are likely to further mature with time. ${ }^{81}$

\section{Concentric versus eccentric filter}

Concentric and eccentric distal protection devices differ based on the position of the wire that tethers the filter: centered versus to the side. Although one study identified no difference between filter type,,$^{82}$ another study reported a statistically significant decrease in embolic events with eccentric filters when analyzing all clinical findings, including 
transient ischemic attacks. ${ }^{39}$ However, this difference was not significant when transient clinical findings were excluded and only stroke and death were analyzed. Eccentric filters may engage the vessel wall more stably, allowing for better embolization protection.

\section{Distal occlusion}

Distal occlusion, as opposed to distal filtration, involves isolation of the distal cerebrovascular distribution from the atherosclerotic carotid segment being manipulated. This can be most simply done with temporary balloon occlusion, which was the first distal embolization protection mechanism reported. ${ }^{83}$ A more sophisticated approach is required to ensure that the embolic material is cleared before the balloon is removed. This is accomplished by applying suction to the sheath proximally or attempting to flush the embolic material proximally in hope of driving the debris into the external carotid system. The GuardWire Protection system (PercuSurge, Sunnyvale, CA, USA), for example, is designed for distal occlusion that is supplemented with an aspiration catheter called the Export (Medtronic). Despite the difficulties associated with debris removal with distal occlusion devices rather than distal protection devices, there is likely a decreased risk of device-induced vasospasm with balloon devices compared to filter devices. A significantly greater likelihood of the need for unprotected predilation was found with distal filter devices compared to distal balloon occlusion devices. ${ }^{39,84}$ Some authors recommend the use of filter devices in preference to balloon occlusion because of a somewhat lower risk of distal embolization, unless the vessels are tortuous and critically narrowed. ${ }^{85}$ Though concern has been expressed regarding increased radiation exposure with the added use of distal embolic protection devices, this has not been borne out by quantitative dosimetric studies. ${ }^{86}$

\section{Flow reversal}

Proximal occlusion aims not to isolate the diseased area undergoing intervention from the distal area but rather to create flow reversal from contralateral carotid and vertebrobasilar collaterals intracranially, thereby flushing emboli proximally into the CCA. Although endarterectomy has the advantage of allowing the placement of a shunt to direct flow from proximal to the CCA clamp to distal to the ICA clamp, yet another maneuver utilized in endarterectomy is replicated by flow reversal technology. Unclamping is performed in a specific order - first the ICA, then the ECA, and finally the CCA - to allow for temporary flow reversal and flushing of potentially embolic material into the extracranial carotid circulation. An advantage of proximal occlusion devices over distal protection devices is that the lesion is not crossed in an unprotected state.

The initial introduction of flow reversal technology for proximal embolic protection was met with skepticism given the significantly lower resistance bed that comprises the intracranial carotid system compared to the extracranial carotid system; even small extracranial collateral communications from the external carotid or vertebrobasilar system may compromise the ability to achieve meaningful flow reversal. Early authors argued that to achieve flow reversal, one must first induce flow stasis by placing the occlusive balloon distal to the ECA takeoff; and if this is done, clearance of embolic materials becomes problematic. ${ }^{30}$

A creative solution to this dilemma was the development of a proximal protection device in which a triple-lumen catheter with a double-balloon was utilized to occlude the CCA and ECA; the reversed flow was then directed through the catheter to a filtered external femoral venous system. ${ }^{87}$ The popularity of proximal protection increased with the introduction of sophisticated technologies, such as the GORE Flow Reversal and Mo.Ma systems (Table 3). Although the GORE system induces true flow reversal, as described above, Mo.Ma is simply a focal flow arrest without any venous return. Trials and meta-analyses confirm a 30-day stroke risk of $<2 \%$ associated with carotid stenting using flow reversal with both systems. ${ }^{88-92}$ It should be noted that there is a reported intolerance to flow arrest or flow reversal in a small subset of patients $(<2 \%)$ with isolated intracranial circulation.

An innovative approach aimed at obviating the need for accessing an unfavorable aortic arch is being evaluated in the Reverse Flow Used During Carotid Artery Stenting Procedure safety and efficacy study. The MICHI

Table 3 Proximal embolization protection devices

\begin{tabular}{llll}
\hline Device & Manufacturer & $\begin{array}{l}\text { External } \\
\text { carotid } \\
\text { artery } \\
\text { occlusion }\end{array}$ & Flow reversal \\
\hline Gore Flow & WL Gore and & $\mathrm{Y}$ & $\mathrm{Y}$ \\
Reversal & Associates (Flagstaff, & & \\
System & Arizona, USA) & $\mathrm{N}$ (focal flow \\
Mo.Ma & Medtronic & & arrest without \\
& (Minneapolis, & & venous return) \\
MICHI & MN, USA) & $\mathrm{N}$ & \\
Neuroprotection & Silk Road & & \\
System & Medical & & \\
& USA) & & \\
\hline
\end{tabular}

Abbreviations: $\mathrm{N}$, no; $\mathrm{Y}$, yes. 
Neuroprotection System (Silk Road Medical Inc., Sunnyvale, CA, USA) has demonstrated initial safety and noninferiority to historical endarterectomy data ${ }^{93}$ using direct carotid puncture access to establish flow reversal and diversion into the femoral venous system with the intent to maximize the interventionist's control of flow parameters. A case in which this transcervical access neuroprotection system was used for carotid stenting is illustrated in Figure 1.

\section{Comparison of embolization prevention devices}

Variable results with embolic protection devices have been reported. Recent MR diffusion imaging and ultrasound transcranial Doppler data have shown embolic events to be less common with flow reversal than distal filter protection. ${ }^{94}$ The opposite conclusion was reached by another group studying postprocedure follow-up MR imaging diffusion restriction. ${ }^{95}$ The results of a study comparing carotid stenting with flow reversal, carotid stenting with distal filter protection, and endarterectomy suggest that the increased risk of perioperative stroke in carotid stenting compared to endarterectomy may be applicable to stenting with distal filter devices but not with flow reversal. ${ }^{96}$ However, no significant differences among these techniques were found when long-term outcomes, such as death and neurological disability, were assessed. Another study found no difference between distal and proximal protection outcomes but noted that distal filters were used in more symptomatic and complex lesions as determined by plaque ulceration, calcification, and length. ${ }^{97}$ The variable results may be due to the novelty of the various embolic-protection devices and their fairly recent introduction into broad use. Flow-reversal is associated with approximately five more steps than distal protection, perhaps making the use of flow-reversal devices more learning-curve and operatorexperience dependent. ${ }^{98}$

\section{Modeling and risk stratification}

As stated above in reference to the Wallstent, one problem that is commonly encountered during carotid stenting is the inability to predict the exact final position of the stent. The use of finite-element analysis to study the effect of carotid stenting on each individual vessel wall is currently a costly and lengthy process that requires several days and significant technological resource expenditure. With improvements in modeling efficiency and computational technology, such analyses may in the future be a helpful addition to clinical practice. ${ }^{99}$
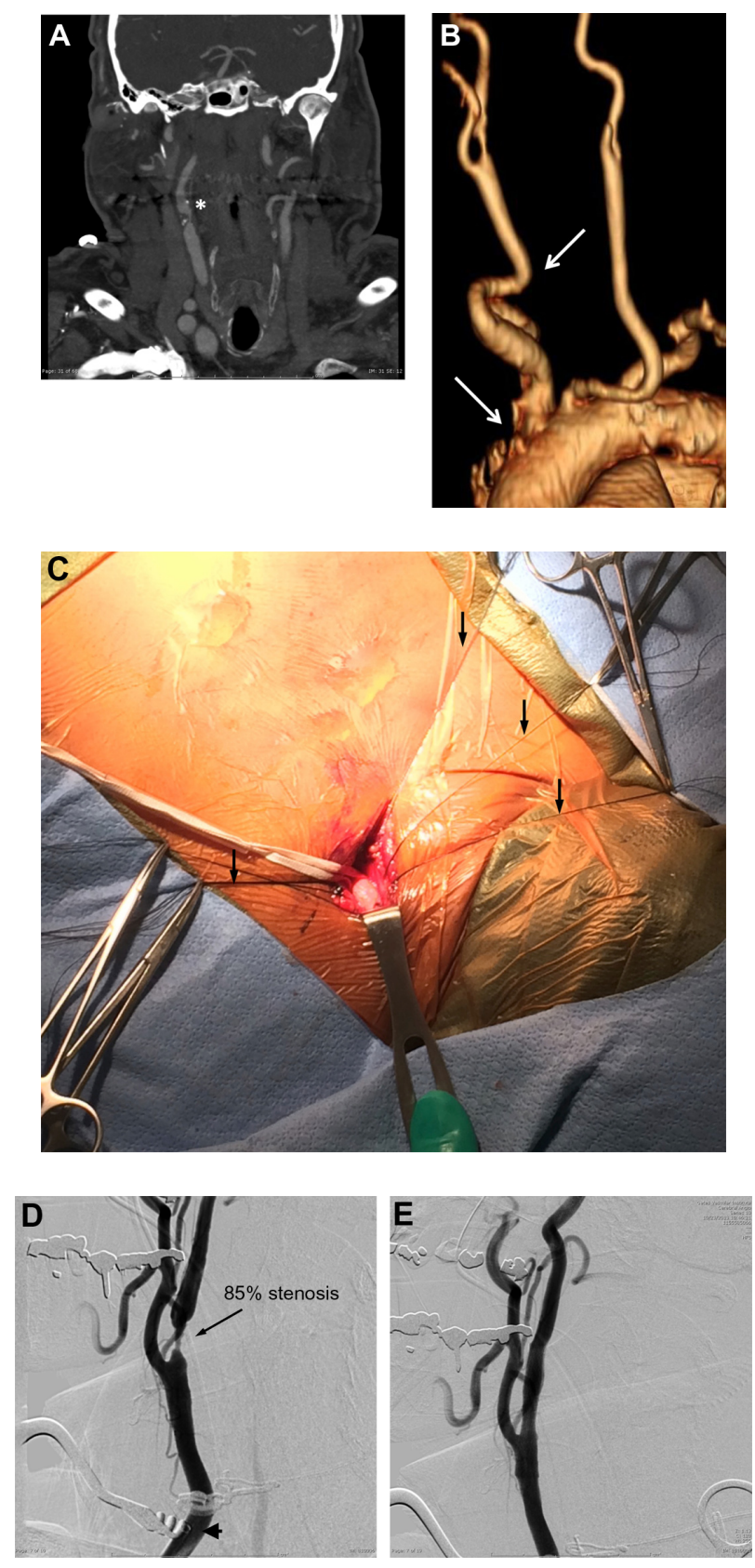

Figure I Case illustration of the Reverse Flow Used During Carotid Artery Stenting Procedure (ROADSTER).

Notes: A 73-year-old man with multiple medical comorbidities, including coronary artery disease status post recent coronary artery bypass grafting, hypertension, and diabetes mellitus, was found to have asymptomatic severe right carotid stenosis on a cervical computed tomographic (CT) angiogram (A). The patient was a poor candidate for carotid endarterectomy owing to body habitus and high lesion (up to C2 vertebral body) and a poor candidate for transfemoral carotid artery stenting due to arch anatomy and a tortuous proximal right common carotid artery (CCA) (B, arrows in CT angiogram three-dimensional reconstruction). He was enrolled in the ROADSTER study and treated via direct carotid artery access. A small incision was made above the right clavicle, and the right CCA was identified and isolated (C, intraoperative photograph). Note the importance of tack-up sutures (arrows) in the carotid sheath that elevated the CCA to the body surface for direct access. After insertion of an arterial access sheath and the $\mathrm{MICHI}$ neuroprotection system (Silk Road Medical, Sunnyvale, California, USA) (D, arrowhead), an angiogram from the right CCA demonstrated $85 \%$ carotid stenosis (arrow). After successfully placing an Xact tapered stent $(8 \times 6 \times 40 \mathrm{~mm}$; Abbott Laboratories, Abbott Park, Illinois, USA) and performing balloon angioplasty, an angiogram from the right CCA (E) showed significantly improved vessel caliber and good stent apposition. 
Carotid tortuosity can be categorized and quantified for risk-stratification on the basis of an intraprocedural angiogram or a preprocedural computed tomographic or MR luminogram. ${ }^{55}$ A group of clinicians in Poland have championed a "tailored" carotid artery stenting algorithm for the elderly; they posit that an intimate knowledge of the specific benefits and characteristics of each device and tailoring the specific combination of devices to the particular vessel anatomy, pathological process, and radiographic qualities of the patient may be especially important in older patients in whom the risks of carotid stenting are especially prominent. ${ }^{100}$
Though at this time insufficiently generalizable or reproducible, a systematic, reportable algorithm may ensue with sufficient experience and effort.

\section{Intravascular ultrasound}

Ultrasound-based technologies and techniques can be used to identify and crudely quantify the echolucency of carotid plaque, which may be a marker for embolic potential. ${ }^{101}$ When choosing devices, relative embolic risk of the devices under consideration and characteristics of the patient's plaque can be taken into account. Intravascular ultrasound (IVUS) is
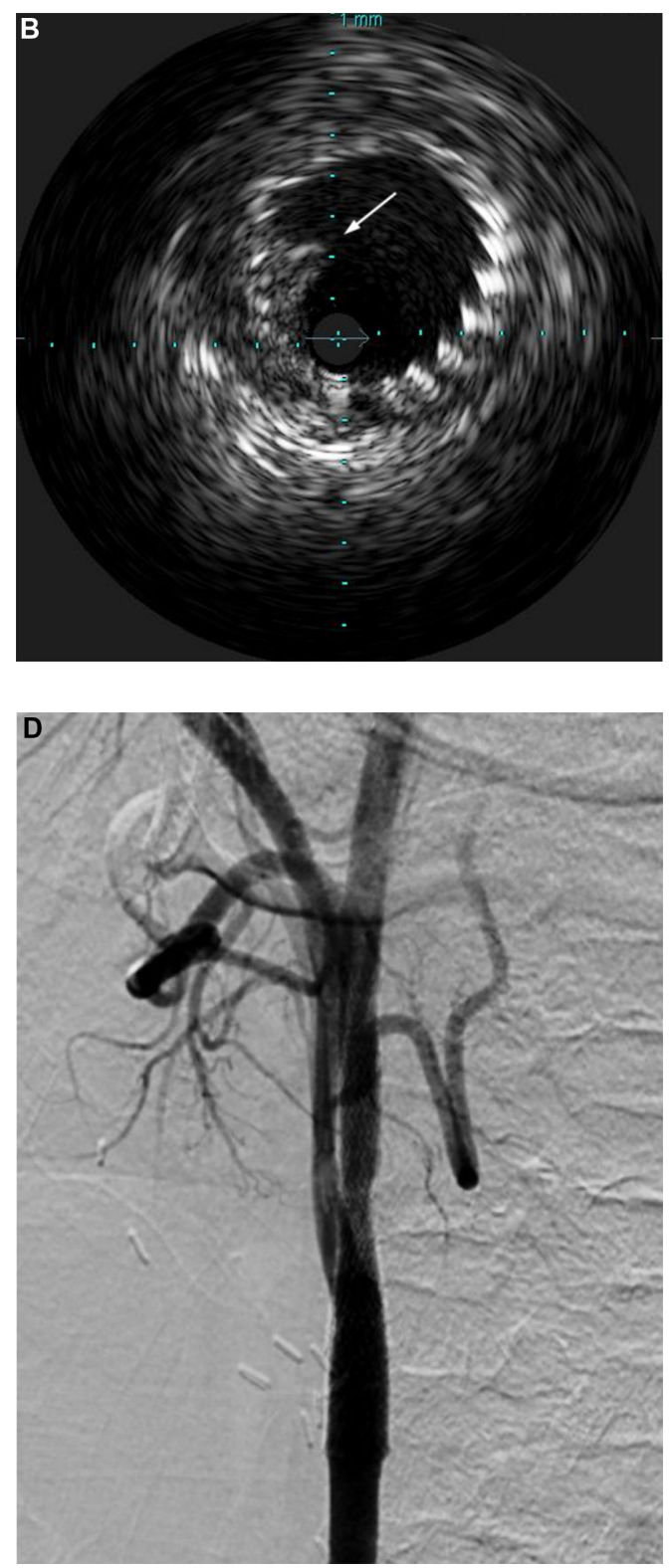

Figure 2 Case illustration of the utility of intravascular ultrasound (IVUS).

Notes: A 60 -year-old man presented with transient dysphasia and was found to have left carotid artery stenosis on angiography (A). After successfully placing an $8 \mathrm{~mm} \times 40 \mathrm{~mm}$ carotid Wallstent (Boston Scientific, Natick, MA, USA), IVUS examination demonstrated intraluminal thrombus (B, arrow), which did not resolve after aspiration. A second Wallstent ( $8 \mathrm{~mm} \times 30 \mathrm{~mm}$ ) was placed to cover the thrombus (C), and poststenting angiogram from the left CCA showed good carotid revascularization (D). Abbreviation: CCA, common carotid artery. 
not currently equipped to provide sophisticated quantitative data. Nevertheless, it provides real-time plaque architecture data that has been shown to have good predictive value for embolic potential. ${ }^{102-104}$ An ex vivo study has demonstrated good concordance between plaque morphology on IVUS and its histological correlates. ${ }^{105}$ The utility of IVUS in the setting of intraluminal thrombus encountered during carotid stenting is illustrated in Figure 2. It is also important to note that IVUS provides superior intraluminal visualization as compared to angiography, particularly poststenting and angioplasty, allowing visualization of plaque prolapse through the tines of the stent, which can be addressed prior to removal of protection devices. This is particularly germane in proximal protection cases where IVUS can be performed while the carotid artery is still under flow reversal/arrest so no anterograde injection of contrast material, which can carry embolic debris, is required before confirming plaque constraint and optimal stent placement.

\section{Future directions}

A novel carotid stent (Gore Scaffold; WL Gore and Associates) is being evaluated in a trial that enrolled its first patient in late 2013 (Gore Carotid Stent Clinical Study for the treatment of carotid Artery stenosis in patients at increased risk For adverse events From CarOtid enDarterectomy [SCAFFOLD]). The Scaffold stent has an open-cell design that is left uncovered on the outside with a polymer film coat on the inside. The aim is to improve plaque stabilization and decrease distal embolic events with the aid of the internal coating which also has a layer of bound heparin. The design of the Casper stent (MicroVention, Tustin, CA, USA) also embraces this similar new-generation technology.

Intravascular ultrasonography allows us to address concerns associated with the use of proximal protection devices. The adjunctive use of this technology during carotid stenting requires further systematic study from device integration and practice protocol perspectives.

\section{Conclusion}

Advances in endovascular approaches to carotid artery revascularization include stent and neuroprotection technologies and techniques, as well as therapies for subsequent restenosis. Intimate knowledge of device technology, along with the flaws and advantages of each technology, is essential to tailoring care to the particular risk profile of a patient. Better designed prospective trials and registries are needed to further delineate the unique indications for new sophisticated technologies.

\section{Acknowledgments}

The authors thank Paul H Dressel, BFA for assistance with preparation of the illustrations and Debra J Zimmer for editorial assistance.

\section{Author contribution}

All authors are responsible for concepts and design, and all authors contributed intellectually. All authors acquired, analyzed, and interpreted the data. The manuscript was prepared by Morr. All authors reviewed and made critical revision of the manuscript.

\section{Disclosure}

Siddiqui's research grants (not related to present study) include National Institutes of Health (coinvestigator: NINDS 1R01NS064592-01A1 and NIBIB5RO1 EB002873-07), University at Buffalo (Research Development Award). Financial interests include Hotspur, Intratech Medical, StimSox, Valor Medical, Blockade Medical, Lazarus Effect; associations as consultant include Codman and Shurtleff, Inc., Concentric Medical, Covidien Vascular Therapies, GuidePoint Global Consulting, Penumbra, Stryker Neurovascular, Pulsar Vascular; speakers' bureaus include Codman and Shurtleff, Genentech; national steering committees member for Penumbra 3D Separator Trial, Covidien SWIFT PRIME Trial; advisory board involvement with Codman and Shurtleff, Covidien Vascular Therapies; honoraria incurred from Abbott Vascular and Codman and Shurtleff, Inc. for training other neurointerventionists in carotid stenting and for training physicians in endovascular stenting for aneurysms. Lin and Morr report no conflicts of interest in this work.

\section{References}

1. Hunt JR. Hunt: the role of the carotid arteries: the role of the carotid arteries, in the causation of vascular lesions of the brain, with remarks on certain special features of the symptomatology. 1914. Am J Med Sci. 2013;346(6):504-509.

2. Fisher M. Occlusion of the internal carotid artery. AMA Arch Neurol Psychiatry. 1951;65(3):346-377.

3. North American Symptomatic Carotid Endarterectomy Trial Collaborators. Beneficial effect of carotid endarterectomy in symptomatic patients with high-grade carotid stenosis. N Engl J Med. 1991;325(7): 445-453.

4. MRC European Carotid Surgery Trial: interim results for symptomatic patients with severe $(70 \%-99 \%)$ or with mild $(0 \%-29 \%)$ carotid stenosis. European Carotid Surgery Trialists' Collaborative Group. Lancet. 1991;337(8752):1235-1243.

5. Mayberg MR, Wilson SE, Yatsu F, et al. Carotid endarterectomy and prevention of cerebral ischemia in symptomatic carotid stenosis. Veterans Affairs Cooperative Studies Program 309 Trialist Group. JAMA. 1991;266(23):3289-3294. 
6. Brott TG, Halperin JL, Abbara S, et al. 2011 ASA/ACCF/AHA/ AANN/AANS/ACR/ASNR/CNS/SAIP/SCAI/SIR/SNIS/SVM/SVS guideline on the management of patients with extracranial carotid and vertebral artery disease: executive summary: a report of the American College of Cardiology Foundation/American Heart Association Task Force on Practice Guidelines, and the American Stroke Association, American Association of Neuroscience Nurses, American Association of Neurological Surgeons, American College of Radiology, American Society of Neuroradiology, Congress of Neurological Surgeons, Society of Atherosclerosis Imaging and Prevention, Society for Cardiovascular Angiography and Interventions, Society of Interventional Radiology, Society of NeuroInterventional Surgery, Society for Vascular Medicine, and Society for Vascular Surgery. J Am Coll Cardiol. 2011;57(8):1002-1044.

7. Brott TG, Hobson RW, Howard G, et al; CREST Investigators. Stenting versus endarterectomy for treatment of carotid-artery stenosis. $N$ Engl J Med. 2010;363(1):11-23.

8. Ischinger TA. Carotid stenting: which stent for which lesion? J Interv Cardiol. 2001;14(6):617-623.

9. Mathur A, Dorros G, Iyer SS, Vitek JJ, Yadav SS, Roubin GS. Palmaz stent compression in patients following carotid artery stenting. Cathet Cardiovasc Diagn. 1997;41(2):137-140.

10. Serruys PW, Strauss BH, de Feyter P, Urban P. The Wallstent: a selfexpanding stent. J Invasive Cardiol. 1991;3(3):127-134.

11. von Birgelen C, Gil R, Ruygrok P, et al. Optimized expansion of the Wallstent compared with the Palmaz-Schatz stent: on-line observations with two- and three-dimensional intracoronary ultrasound after angiographic guidance. Am Heart J. 1996;131(6):1067-1075.

12. Qin F, Panetta TF. Vascular stents. In: Moore WS, Ahn SS, editors. Endovascular Surgery. Philadelphia, PA: Saunders; 2011:89-105.

13. Boyne PJ. Free grafting of traumatically displaced or resected mandibular condyles. J Oral Maxillofac Surg. 1989;47(3):228-232.

14. Cantore GP, Delfini R, Mariottini A, Santoro A, Cascone P. Anterior displacement of the mandible for better exposure of the distal segment of the extracranial carotid artery. Acta Neurochir (Wien). 1987;86(1-2): 56-60.

15. Fisher DF, Clagett GP, Parker JI, et al. Mandibular subluxation for high carotid exposure. J Vasc Surg. 1984;1(6):727-733.

16. Guterman LR, Fessler RD, Hopkins LN. Cervical carotid revascularization. Neurosurg Clin N Am. 2000;11(1):39-48, viii.

17. White CJ, Ramee SR, Collins TJ, Jenkins JS, Reilly JP, Patel RA. Carotid artery stenting: patient, lesion, and procedural characteristics that increase procedural complications. Catheter Cardiovasc Interv. 2013;82(5):715-726.

18. Naylor AR, Bolia A, Abbott RJ, et al. Randomized study of carotid angioplasty and stenting versus carotid endarterectomy: a stopped trial. J Vasc Surg. 1998;28(2):326-334.

19. Endovascular versus surgical treatment in patients with carotid stenosis in the Carotid and Vertebral Artery Transluminal Angioplasty Study (CAVATAS): a randomised trial. Lancet. 2001;357(9270):1729-1737.

20. Mas JL, Chatellier G, Beyssen B, et al; EVA-3S Investigators. Endarterectomy versus stenting in patients with symptomatic severe carotid stenosis. N Engl J Med. 2006;355(16):1660-1671.

21. Ringleb PA, Allenberg J, Brückmann H, et al; SPACE Collaborative Group. 30 day results from the SPACE trial of stent-protected angioplasty versus carotid endarterectomy in symptomatic patients: a randomised non-inferiority trial. Lancet. 2006;368(9543): 1239-1247.

22. Yadav JS, Wholey MH, Kuntz RE, et al; Stenting and Angioplasty with Protection in Patients at High Risk for Endarterectomy Investigators. Protected carotid-artery stenting versus endarterectomy in high-risk patients. N Engl J Med. 2004;351(15):1493-1501.

23. Mas JL, Trinquart L, Leys D, et al; EVA-3S investigators. Endarterectomy Versus Angioplasty in Patients with Symptomatic Severe Carotid Stenosis (EVA-3S) trial: results up to 4 years from a randomised, multicentre trial. Lancet Neurol. 2008;7(10):885-892.
24. Eckstein HH, Ringleb P, Allenberg JR, et al. Results of the StentProtected Angioplasty versus Carotid Endarterectomy (SPACE) study to treat symptomatic stenoses at 2 years: a multinational, prospective, randomised trial. Lancet Neurol. 2008;7(10):893-902.

25. Ederle J, Dobson J, Featherstone RL, et al; International Carotid Stenting Study investigators. Carotid artery stenting compared with endarterectomy in patients with symptomatic carotid stenosis (International Carotid Stenting Study): an interim analysis of a randomised controlled trial. Lancet. 2010;375(9719):985-997.

26. Bonati LH, Jongen LM, Haller S, et al; ICSS-MRI study group. New ischaemic brain lesions on MRI after stenting or endarterectomy for symptomatic carotid stenosis: a substudy of the International Carotid Stenting Study (ICSS). Lancet Neurol. 2010;9(4): 353-362.

27. Lal BK, Meschia JF, Brott TG. CREST-2: guiding treatments for asymptomatic carotid disease. Endovascular Today. 2013;(September):73-76.

28. Vorwerk D, Günther RW. Stent placement in iliac arterial lesions: three years of clinical experience with the Wallstent. Cardiovasc Intervent Radiol. 1992;15(5):285-290.

29. Zollikofer CL, Antonucci F, Pfyffer M, et al. Arterial stent placement with use of the Wallstent: midterm results of clinical experience. Radiology. 1991;179(2):449-456.

30. Williams JS. Mechanical devices used for carotid stenting. Tech Vasc Interv Radiol. 2000;3(2):102-113.

31. Tadros RO, Spyris CT, Vouyouka AG, et al. Comparing the embolic potential of open and closed cell stents during carotid angioplasty and stenting. J Vasc Surg. 2012;56(1):89-95.

32. Gurbel PA, Callahan KP, Malinin AI, Serebruany VL, Gillis J. Could stent design affect platelet activation? Results of the Platelet Activation in STenting (PAST) Study. J Invasive Cardiol. 2002;14(10): 584-589.

33. Hong MK, Mintz GS, Lee CW, et al. Incidence, mechanism, predictors, and long-term prognosis of late stent malapposition after bare-metal stent implantation. Circulation. 2004;109(7):881-886.

34. Stoeckel D, Bonsignore C, Duda S. A survey of stent designs. Minim Invasive Ther Allied Technol. 2002;11(4):137-147.

35. Pierce DS, Rosero EB, Modrall JG, et al. Open-cell versus closed-cell stent design differences in blood flow velocities after carotid stenting. J Vasc Surg. 2009;49(3):602-606; discussion 606.

36. Timaran CH, Rosero EB, Higuera A, Ilarraza A, Modrall JG, Clagett GP. Randomized clinical trial of open-cell vs closed-cell stents for carotid stenting and effects of stent design on cerebral embolization. $J$ Vasc Surg. 2011;54(5):1310-1316. e1; discussion 1316.

37. Grunwald IQ, Reith W, Karp K, et al. Comparison of stent free cell area and cerebral lesions after unprotected carotid artery stent placement. Eur J Vasc Endovasc Surg. 2012;43(1):10-14.

38. Bosiers M, de Donato G, Deloose K, et al. Does free cell area influence the outcome in carotid artery stenting? Eur J Vasc Endovasc Surg. 2007;33(2):135-141; discussion 142-143.

39. Hart JP, Peeters P, Verbist J, Deloose K, Bosiers M. Do device characteristics impact outcome in carotid artery stenting? J Vasc Surg. 2006;44(4):725-730; discussion 730-731.

40. Schillinger M, Gschwendtner M, Reimers B, et al. Does carotid stent cell design matter? Stroke. 2008;39(3):905-909.

41. Auricchio F, Conti M, Ferraro M, Reali A. Evaluation of carotid stent scaffolding through patient-specific finite element analysis. Int J Numer Method Biomed Eng. 2012;28(10):1043-1055.

42. Kabinejadian F, Cui F, Zhang Z, Ho P, Leo HL. A novel carotid covered stent design: in vitro evaluation of performance and influence on the blood flow regime at the carotid artery bifurcation. Ann Biomed Eng. 2013;41(9):1990-2002.

43. Greil O, Kleinschmidt T, Weiss W, et al. Flow velocities after carotid artery stenting: impact of stent design. A fluid dynamics study in a carotid artery model with laser Doppler anemometry. Cardiovasc Intervent Radiol. 2005;28(1):66-76. 
44. Müller-Hülsbeck S, Jahnke T, Stolzmann P, Paulsen F, Wenke R, Heller M. A new concept for covered stent protected carotid angioplasty: an ex vivo study. Rofo. 2003;175(12):1634-1638.

45. Schillinger M, Dick P, Wiest G, et al. Covered versus bare selfexpanding stents for endovascular treatment of carotid artery stenosis: a stopped randomized trial. $J$ Endovasc Ther. 2006;13(3):312-319.

46. Szólics A, Sztriha LK, Szikra P, Szólics M, Palkó A, Vörös E. The use of covered stents for the endovascular treatment of extracranial internal carotid artery stenosis: a prospective study with a 5-year follow-up. Eur Radiol. 2010;20(7):1772-1776.

47. Farhatnia Y, Tan A, Motiwala A, Cousins BG, Seifalian AM. Evolution of covered stents in the contemporary era: clinical application, materials and manufacturing strategies using nanotechnology. Biotechnol Adv. 2013;31(5):524-542.

48. Siddiqui AH, Chen PR. Intracranial collateral anastomoses: relevance to endovascular procedures. Neurosurg Clin N Am. 2009;20(3): 279-296.

49. Brown KE, Usman A, Kibbe MR, et al. Carotid stenting using tapered and nontapered stents: associated neurological complications and restenosis rates. Ann Vasc Surg. 2009;23(4):439-445.

50. Chang DW, Schubart PJ, Veith FJ, Zarins CK. A new approach to carotid angioplasty and stenting with transcervical occlusion and protective shunting: Why it may be a better carotid artery intervention. J Vasc Surg. 2004;39(5):994-1002.

51. Larrazabal R, Klurfan P, Sarma D, Gunnarsson T. Surgical exposure of the carotid artery for endovascular interventional procedures. Acta Neurochir (Wien). 2010;152(3):537-544.

52. Samaniego EA, Dabus G, Raju R, Tsoukas AI, Linfante I. Intracranial angioplasty and stenting through direct carotid puncture. J Neuroimaging. 2013;23(2):207-210.

53. Dumont TM, Mokin M, Wach MM, et al. Understanding risk factors for perioperative ischemic events with carotid stenting: is patient age over 80 years or is unfavorable arch anatomy to blame? J Neurointerv Surg. 2014;6(3):219-224.

54. Lam RC, Lin SC, DeRubertis B, Hynecek R, Kent KC, Faries PL. The impact of increasing age on anatomic factors affecting carotid angioplasty and stenting. J Vasc Surg. 2007;45(5):875-880.

55. Lin SC, Trocciola SM, Rhee J, et al. Analysis of anatomic factors and age in patients undergoing carotid angioplasty and stenting. Ann Vasc Surg. 2005;19(6):798-804.

56. Chakhtoura EY, Hobson RW 2nd, Goldstein J, et al. In-stent restenosis after carotid angioplasty-stenting: incidence and management. $J$ Vasc Surg. 2001;33(2):220-225; discussion 225-226.

57. Bendok BR, Roubin GS, Katzen BT, et al. Cutting balloon to treat carotid in-stent stenosis: technical note. J Invasive Cardiol. 2003;15(4):227-232.

58. Heck D. Results of cutting balloon angioplasty for carotid artery in-stent restenosis in six patients: description of the technique, longterm outcomes, and review of the literature. J Neurointerv Surg. 2009;1(1):48-50.

59. Shah QA, Georgiadis AL, Suri MF, Rodriguez GJ, Qureshi AI. Cutting balloon angioplasty for carotid in-stent restenosis: case reports and review of the literature. $J$ Neuroimaging. 2008;18(4):428-432.

60. Setacci F, Sirignano P, de Donato G, et al. Carotid highly-calcified de novo stenosis and cutting-balloon angioplasty: a tool to prevent haemodynamic depression? J Cardiovasc Surg (Torino). 2009;50(3): 357-364.

61. Montorsi P, Galli S, Ravagnani PM, et al. Drug-eluting balloon for treatment of in-stent restenosis after carotid artery stenting: preliminary report. J Endovasc Ther. 2012;19(6):734-742.

62. Sangiorgi G, Romagnoli E, Biondi-Zoccai G. Commentary: drug-eluting balloons for carotid in-stent restenosis: can this technology deliver the goods? J Endovasc Ther. 2012;19(6):743-748.

63. Ritter MA, Theismann K, Schmiedel M, Ringelstein EB, Dittrich R. Vascularization of carotid plaque in recently symptomatic patients is associated with the occurrence of transcranial microembolic signals. Eur J Neurol. 2013;20(8):1218-1221.
64. Gray WA, Hopkins LN, Yadav S, et al; ARCHeR Trial Collaborators. Protected carotid stenting in high-surgical-risk patients: the ARCHeR results. J Vasc Surg. 2006;44(2):258-268.

65. Iyer SS, White CJ, Hopkins LN, et al; BEACH Investigators. Carotid artery revascularization in high-surgical-risk patients using the Carotid WALLSTENT and FilterWire EX/EZ: 1-year outcomes in the BEACH Pivotal Group. J Am Coll Cardiol. 2008;51(4):427-434.

66. Matsumura JS, Gray W, Chaturvedi S, Yamanouchi D, Peng L, Verta P. Results of carotid artery stenting with distal embolic protection with improved systems: Protected Carotid Artery Stenting in Patients at High Risk for Carotid Endarterectomy (PROTECT) trial. J Vasc Surg. 2012;55(4):968-976. e5.

67. Angelini A, Reimers B, Della Barbera M, et al. Cerebral protection during carotid artery stenting: collection and histopathologic analysis of embolized debris. Stroke. 2002;33(2):456-461.

68. Henry M, Amor M, Henry I, et al. Carotid stenting with cerebral protection: first clinical experience using the PercuSurge GuardWire system. J Endovasc Surg. 1999;6(4):321-331.

69. Reimers B, Corvaja N, Moshiri S, et al. Cerebral protection with filter devices during carotid artery stenting. Circulation. 2001;104(1):12-15.

70. Schlüter M, Tübler T, Steffens JC, Mathey DG, Schofer J. Focal ischemia of the brain after neuroprotected carotid artery stenting. J Am Coll Cardiol. 2003;42(6):1007-1013.

71. Vos JA, van den Berg JC, Ernst SM, et al. Carotid angioplasty and stent placement: comparison of transcranial Doppler US data and clinical outcome with and without filtering cerebral protection devices in 509 patients. Radiology. 2005;234(2):493-499.

72. Touzé E, Trinquart L, Chatellier G, Mas JL. Systematic review of the perioperative risks of stroke or death after carotid angioplasty and stenting. Stroke. 2009;40(12):e683-e693.

73. Eskandari MK, Najjar SF, Matsumura JS, Kibbe MR, Morasch MD. Technical limitations of carotid filter embolic protection devices. Ann Vasc Surg. 2007;21(4):403-407.

74. Lian X, Liu W, Li M, et al. Risk factors and complications associated with difficult retrieval of embolic protection devices in carotid artery stenting. Cardiovasc Intervent Radiol. 2012;35(1):43-48.

75. Tallarita T, Rabinstein AA, Cloft $\mathrm{H}$, et al. Are distal protection devices 'protective' during carotid angioplasty and stenting? Stroke. 2011;42(7):1962-1966.

76. Kim YW, Kang DH, Hwang JH, Park J, Hwang YH, Kim YS. Rescue strategy for acute carotid stent thrombosis during carotid stenting with distal filter protection using forced arterial suction thrombectomy with a reperfusion catheter of the Penumbra System: a technical note. Acta Neurochir (Wien). 2013;155(8):1583-1588

77. Casserly IP, Abou-Chebl A, Fathi RB, et al. Slow-flow phenomenon during carotid artery intervention with embolic protection devices: predictors and clinical outcome. J Am Coll Cardiol. 2005;46(8): 1466-1472.

78. Gray WA, Yadav JS, Verta P, et al. The CAPTURE registry: results of carotid stenting with embolic protection in the post approval setting. Catheter Cardiovasc Interv. 2007;69(3):341-348.

79. Stingele R, Berger J, Alfke K, et al; SPACE investigators. Clinical and angiographic risk factors for stroke and death within 30 days after carotid endarterectomy and stent-protected angioplasty: a subanalysis of the SPACE study. Lancet Neurol. 2008;7(3):216-222.

80. Zahn R, Ischinger T, Hochadel M, et al; Arbeitsgemeinschaft Leitende Kardiologische Krankenhausärzte. Carotid artery stenting in octogenarians: results from the ALKK Carotid Artery Stent (CAS) Registry. Eur Heart J. 2007;28(3):370-375.

81. Metzger DC. Embolic protection in carotid artery stenting: new options. Tech Vasc Interv Radiol. 2011;14(2):86-94.

82. Iyer V, de Donato G, Deloose K, et al. The type of embolic protection does not influence the outcome in carotid artery stenting. J Vasc Surg. 2007;46(2):251-256.

83. Théron J, Cosgrove R, Melanson D, Ethier R. Embolization with temporary balloon occlusion of the internal carotid or vertebral arteries. Neuroradiology. 1986;28(3):246-253. 
84. Wholey MH, Finol E, Wholey M, Scotti CM, Verdinelli I. How effective are distal embolic protection filters in carotid stenting? Clinical and benchtop testing results. Am J Cardiol. 2005;96(Suppl 7A):77H.

85. Powell RJ, Alessi C, Nolan B, et al. Comparison of embolization protection device-specific technical difficulties during carotid artery stenting. J Vasc Surg. 2006;44(1):56-61.

86. D’Ercole L, Quaretti P, Cionfoli N, et al. Patient dose during carotid artery stenting with embolic-protection devices: evaluation with radiochromic films and related diagnostic reference levels according to factors influencing the procedure. Cardiovasc Intervent Radiol. 2013;36(2):320-329.

87. Parodi JC, Ferreira LM, Sicard G, La Mura R, Fernandez S. Cerebral protection during carotid stenting using flow reversal. J Vasc Surg. 2005;41(3):416-422.

88. Ansel GM, Hopkins LN, Jaff MR, et al; Investigators for the ARMOUR Pivotal Trial. Safety and effectiveness of the INVATEC MO.MA proximal cerebral protection device during carotid artery stenting: results from the ARMOUR pivotal trial. Catheter Cardiovasc Interv. 2010;76(1):1-8.

89. Bersin RM, Stabile E, Ansel GM, et al. A meta-analysis of proximal occlusion device outcomes in carotid artery stenting. Catheter Cardiovasc Interv. 2012;80(7):1072-1078.

90. Montorsi P, Caputi L, Galli S, et al. Microembolization during carotid artery stenting in patients with high-risk, lipid-rich plaque. A randomized trial of proximal versus distal cerebral protection. J Am Coll Cardiol. 2011;58(16):1656-1663.

91. Nikas D, Reith W, Schmidt A, et al. Prospective, multicenter European study of the GORE flow reversal system for providing neuroprotection during carotid artery stenting. Catheter Cardiovasc Interv. 2012;80(7):1060-1068.

92. Stabile E, Rubino P, Montorsi P. Clamping intolerance during proximal protected carotid artery stenting. Catheter Cardiovasc Interv. 2013;82(1):60-61.

93. Pinter L, Ribo M, Loh C, et al. Safety and feasibility of a novel transcervical access neuroprotection system for carotid artery stenting in the PROOF Study. J Vasc Surg. 2011;54(5):1317-1323.

94. Goode SD, Hoggard N, Macdonald S, Evans DH, Cleveland TJ, Gaines PA. Assessment of reverse flow as a means of cerebral protection during carotid artery stent placement with diffusion-weighted and transcranial Doppler imaging. J Vasc Interv Radiol. 2013;24(4):528-533.
95. Castro-Afonso LH, Abud LG, Rolo JG, et al. Flow reversal versus filter protection: a pilot carotid artery stenting randomized trial. Circ Cardiovasc Interv. 2013;6(5):552-559.

96. Brewster LP, Beaulieu R, Corriere MA, et al. Carotid revascularization outcomes comparing distal filters, flow reversal, and endarterectomy. J Vasc Surg. 2011;54(4):1000-1004; discussion 1004-1005.

97. Zahn R, Ischinger T, Mark B, et al; Arbeitsgemeinschaft Leitende Kardiologische Krankenhausärzte (ALKK). Embolic protection devices for carotid artery stenting: is there a difference between filter and distal occlusive devices? J Am Coll Cardiol. 2005;45(11):1769-1774.

98. Stabile E, Esposito G. Operator's experience is the most efficient embolic protection device for carotid artery stenting. Circ Cardiovasc Interv. 2013;6(5):496-497.

99. Auricchio F, Conti M, Ferrara A, Morganti S, Reali A. Patient-specific finite element analysis of carotid artery stenting: a focus on vessel modeling. Int J Numer Method Biomed Eng. 2013;29(6):645-664.

100. Dzierwa K, Pieniazek P, Tekieli L, et al. Carotid artery stenting according to the "tailored CAS" algorithm performed in the very elderly patients: the thirty day outcome. Catheter Cardiovasc Interv. 2013;82(5):681-688.

101. Mathiesen EB, Bønaa KH, Joakimsen O. Echolucent plaques are associated with high risk of ischemic cerebrovascular events in carotid stenosis: the tromsø study. Circulation. 2001;103(17):2171-2175.

102. Clair DG, Hopkins LN, Mehta M, et al; EMPiRE Clinical Study Investigators. Neuroprotection during carotid artery stenting using the GORE flow reversal system: 30-day outcomes in the EMPiRE Clinical Study. Catheter Cardiovasc Interv. 2011;77(3):420-429.

103. Clark DJ, Lessio S, O’Donoghue M, Schainfeld R, Rosenfield K. Safety and utility of intravascular ultrasound-guided carotid artery stenting Catheter Cardiovasc Interv. 2004;63(3):355-362.

104. Wehman JC, Holmes DR Jr, Ecker RD, et al. Intravascular ultrasound identification of intraluminal embolic plaque material during carotid angioplasty with stenting. Catheter Cardiovasc Interv. 2006;68(6):853-857

105. Fuchs M, Heider P, Pelisek J, Poppert H, Eckstein HH. Ex vivo characterization of carotid plaques by intravascular ultrasonography and virtual histology: concordance with real plaque pathomorphology. J Cardiovasc Surg (Torino). Epub December 10, 2013.
Medical Devices: Evidence and Research

\section{Publish your work in this journal}

Medical Devices: Evidence and Research is an international, peerreviewed, open access journal that focuses on the evidence, technology, research, and expert opinion supporting the use and application of medical devices in the diagnosis, treatment and management of clinical conditions and physiological processes. The identification of novel

\section{Dovepress}

devices and optimal use of existing devices which will lead to improved clinical outcomes and more effective patient management and safety is a key feature. The manuscript management system is completely online and includes a quick and fair peer-review system. Visit http://www. dovepress.com/testimonials.php to read real quotes from authors. 